\title{
IMPROVEMENT OF WELDING POWER SOURCES IN ORDER TO INCREASE BURNING STABILITY OF ALTERNATING CURRENT ARC
}

\author{
N.M. MAKHLIN \\ SE Research Engineering Center of Welding and Control in Power Engineering \\ of E.O. Paton Electric Welding Institute, NASU \\ 11 Kazimir Malevich Str., 03680, Kiev, Ukraine. E-mail:electro@paton.kiev.ua
}

\begin{abstract}
The work studies the problems of increase of stability of alternating current arc in arc and plasma welding by means of improvement of welding power sources. It is noted that pulse increase of power source output voltage at arc polarity change, application of inductive-capacitive converters, using the power sources providing close to rectangular current waveform acquired the widest distribution among the well-known methods. It is shown that development of alternating current welding power sources, combining two or several methods and having in its design the circuits or devices providing the possibility to function in a mode of initial arc ignition (striking) as well as in a mode of its burning stabilizing, is the most efficient method. It can be achieved, in particular, by means of building of these circuits or devices in form of generators of high or increased voltage pulses with two independent forming circuits. Several variants of circuit solutions of the improved power sources for alternating current arc welding are given and described. 37 Ref., 7 Figures.
\end{abstract}

Keywords: arc and plasma welding, alternating current, power sources, initial and repeated arc ignition, phase regulation, arc stability, electromagnetic compatibility, inductive-capacitive converters

AC arc and plasma welding in comparison with DC welding has a series of such technological advantages as absence of magnetic blow, possibility of weld formation with favorable geometry parameters and penetration profile as well as producing of more finegrain structure of weld metal and HAZ, including using more efficient modes than in DC welding. AC welding is significantly cost-effective than DC welding. The AC welding power sources differ by simple design and structure and, in the most cases, their efficiency and safety indices are higher than in DC power sources and expenses for their operation and servicing are perceptibly lower [1-6]. In this connection AC is widely used in many branches of industry for manual metal arc welding (MMAW), submerged arc welding (SAW), manual and mechanized consumable electrode inert gas welding (TIG-AC) and other methods of arc and plasma welding.

AC welding in parallel with known advantages has some disadvantages, main of which lies in low stability of arcing process, which is particularly typical for sine wave welding currents of industrial frequencies. It can be related with its periodic extinctions due to deionizing of interelectrode gap, appearing at each change of arc current polarity, i.e. close to its zero values. Therefore, researchers and specialists of welding engineering in course of number of years and up to now try to find the methods and means to increase the

(C) N.M. MAKHLIN, 2016 stability of AC arcs [1, 2, 4, 5, 7-26] among which problem of improvement of welding power sources takes an important place.

Aim of the present work is to study and describe the separate developments, mainly of PWI, directed on increase of stability of AC arc by means of improvement of design and operating algorithms of power part of the welding power sources.

Peculiarities and examples of design of improved alternating current welding power sources. The issues of increase of arc stability in welding current polarity change by means of improvement of welding power sources are reflected in multiple monographs, papers and patents. Significantly substantial theoretical investigations were carried out in this direction, extensive experimental works were performed, different methods for improvement of power sources and engineering solutions, providing realizing of these methods $[1-5,7-21]$ were developed and tested.

Carried investigations determined that one of the mandatory conditions for providing arc re-ignition at its current polarity change is fulfillment of $U_{2}>U_{\text {str }}$ requirement, where $U_{2}$ is the voltage, applied in a gap between electrode and part being welded during time intervals corresponding to arc current zero; $U_{\text {str }}$ is the value of amplitude of arc striking voltage in each semi-period of welding current, called striking peak $[1,2,4,5,15]$. It should be noted that fulfillment of this condition by means of increase of open-circuit 
voltage $U_{\text {op-c }}$ of power source is complicated due to safety requirements, according to which $U_{\text {op.-c }}$ effective value of power sources should not exceed $80 \mathrm{~V}$, and that of amplitude value $113 \mathrm{~V}$. It is also determined that duration of dead time at current polarity change is determined by content of gas in the interelectrode gap and potential of its ionization as well as rate of arc current change $d I_{\mathrm{A}} / d t$, which should be more than $10 \mathrm{kA} / \mathrm{s}$ in order to provide stable arcing. The more $d I_{\mathrm{A}} / d t$ is, the shorter duration of dead time, the more the de-ionizing time and lower $U_{\text {str }}$ value $[1,4$, $5,8]$ are. $d I_{A} / d t$ value with sufficient for practice value can be determined as

$$
d I_{\mathrm{A}} / d t \approx \Delta I_{\mathrm{A}} / d t=I_{\mathrm{A} 0} \omega,
$$

where $I_{\mathrm{A} 0}$ is the amplitude value of arc current; $\omega$ is its angular frequency.

The following methods have got the most widespread distribution among the known methods of increase of stability of AC arc:

- pulse increase of output voltage of power source at arc polarity change, including with the help of application of special pulse voltage booster - stabilizers of arcing;

- application of inductive-capacitive converters (ICC);

- application of power sources providing arc current waveform close to rectangular one;

- combination of several indicated methods.

Pulse increase of output voltage of power source at polarity change is used, in particular, for improvement of power sources, based on single-phase welding transformer with mechanical or electrical regulation and designed for application mainly of $50(60) \mathrm{Hz}$ commercial frequency at MMAW. Regardless the fact that production and use of such power sources is gradually decreasing, a stock of welding transformers being in operation is sufficiently large and only in CIS countries makes hundred thousand of pieces. Therefore, the problem of expansion of their technological capabilities is still relevant [27].

All existing engineering solutions for realizing the method of pulse increase of output voltage of welding transformers assumes application of additional blocks and circuits, providing formation of pulses of voltage which is summed at change of polarity of arc current with voltage of welding transformer secondary winding. At that, these additional blocks or circuits necessarily include auxiliary transformer of limited capacity or additional winding on welding transformer core $[1,2,4,5,9,15]$. Arc re-ignition at arc current polarity change are provided as a result of pulse increase of output voltage $U_{2}$ of power source to $U_{2}>U_{\text {str }}$ value. The disadvantages of known devices, which realize the method of pulse increase of output voltage of

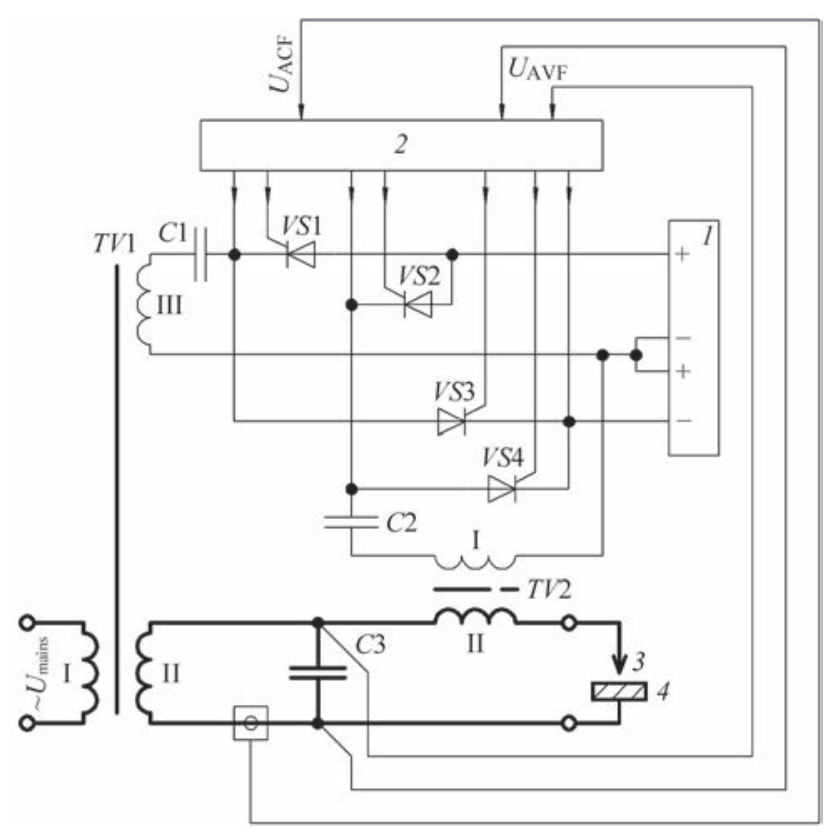

Figure 1. Structure-functional scheme of improved AC power source based on welding transformer with amplitude mechanical or electromechanical regulation (see designations in the text)

power source, are the necessity of somewhat complication and rise of design price of such power sources, absence of possibility of contact-free initial striking of arc, dependence of values of power source output voltage on fluctuations of supply mains voltage.

Figure 1 shows a structural-functional scheme of one of the variants of design of improved power source with pulse increase of output voltage [28].

The power source for AC welding includes regulated (manly mechanically or electromechanically) single-phase welding transformer TV1 with power primary I and secondary II windings and additional winding III as well as striker-stabilizer.

It consists of bi-polar DC source 1, control block (CB) 2, circuit of pulse stabilizing, including capacitor $C 1$, winding III of welding transformer TV1 and key on thyristors VS1 and VS3 as well as circuit for high-voltage pulse generation, formed by capacitor $C 2$, primary winding I of step-up pulse transformer TV2, primary winding II of which has series connection to welding circuit, and key on thyristors VS2 and VS4. Capacitor C3 is designed for protection of welding transformer TV1 from effect of high-voltage pulses.

Initial ignition of the arc in positive or negative supply voltage half-wave of welding transformer TV1 by the signals from $\mathrm{CB} 2$, at the moments when open-circuit voltage $U_{\text {op-ctr }}$ of transformer TV1 is close to reach the amplitude value, promotes for switch of thyristor VS2 or VS4, respectively. This causes oscillatory charge or recharge of capacitor C2 via winding I of step-up transformer TV2. Thyristors VS2 or VS4 automatically switch off at the end of capacitor $C 2$ charge or recharge. Charge or recharge of capacitor $C 2$ on 
winding II of transformer TV2 forms the high-voltage pulse, being injected through protective capacitor $C 3$ in a gap between electrode 3 and part being welded 4 . This provides for impact ionizing of this interelectrode gap, its breakdown and appearance in it of a spark discharge coming into arc one, at which arc current from winding II of welding transformer TV1 starts flowing through the interelectrode gap. Feed of CB 2 signals about switch on of thyristor VS2 or VS4 is terminated after appearance in the interelectrode gap of the stable arc discharge on arc current feedback signal $\left(U_{\mathrm{ACF}}\right)$. Simultaneously, CB 1 starts to generate signals of thyristor VS1 or VS3 switch on at the moments determined by arc voltage feedback signals $\left(U_{\mathrm{AVF}}\right)$ and close to the moments of arc voltage polarity change. Switch on of thyristor VS1 or VS3 provokes charge or recharge of capacitor $C 1$ via winding III of welding transformer TV1. Because of this, the increased-voltage pulse, which is injected in the interelectrode gap and stabilizes arcing, is formed on its winding II. Thyristor VS1 or VS3 is automatically switched off after charging or recharging of capacitor $C 1$.

Among the advantages of this device are efficiency and relative simplicity of circuit and design, amplitude regulation of welding current and stability of coefficient of its form in the whole range of regulation, possibility of application of welding transformer with reduced open-circuit voltage. The disadvantages of this device are impossibility of programming (setting) the welding cycle parameters and performance of modulated current welding modes, loss of some part of power of stabilizing pulses due to shunting effect of protective capacitor $C 3$, necessity in special welding transformer TV1 and specific complication of CB 2, caused by the requirement of separate regulation of thyristors VS1-VS4, impossibility to design the striker-stabilizer as a self-contained unit. Nevertheless, described device has found application in versatile units for MMAW and TIG-AC welding, for example, single-phase welding apparatuses I-025 U3.1 and oth-

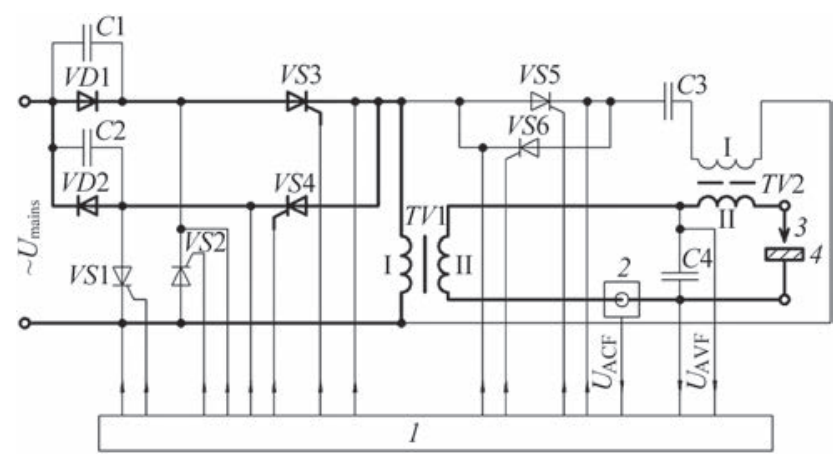

Figure 2. Simplified schematic circuit diagram of power part of improved power source based on TT with phase regulator in the primary circuit: 1 - CB; 2 - arc current probe (for rest designations see the text) er power sources for AC arc welding, designed based on welding transformers with mechanical or electromechanical regulation of welding current.

The power sources, designed using welding transformers with electric regulation, have better weight-dimension indices and wider engineering capabilities in comparison with the AC power sources, designed based on welding transformers with mechanical or electromechanical regulation of arc current. These are so-called thyristor transformers (TT), action of which is based on the method of phase regulation of arc current $[2,4,5,29]$. TT phase regulator consists, as a rule, of two back-to-back connected thyristors and system of their regulation. All known TT can be classified on two main characteristics, i.e. way of providing arc current stability and place of phase regulator location, namely in the primary or secondary circuit of the transformer. In turn, according to the first of these characteristics the TT are divided on two groups. The first includes the transformers with intermittent arc current, i.e. with presence of dead time in each semi-period of this current; the second contains the TT providing continuity of current flow through the interelectrode gap during the whole process of welding (except for short intervals of time at change of arc current polarity).

Figure 2 shows the simplified electrical schematic diagram of power part of improved power source. The scheme is designed according to [30] based on TT containing in its primary circuit a phase regulator on VD1, VD2 diodes and VS3, VS4 thyristors, components of voltage booster assembly (capacitors C1, C2 and thyristors VS1, VS2) and a circuit, having series connection to primary winding I of welding transformer TV1 with developed magnetic dissipation, for formation of the high-voltage pulses (thyristors VS5 and VS6, capacitor C3 and primary winding I of pulse transformer TV2).

Contact-free initial ignition of arc is carried out with the help of high-voltage pulses, injected into the interelectrode gap (gap between electrode 3 and part being welded 4) via protective capacitor $C 4$. After initiation of the spark discharge in the interelectrode gap and its transfer in a stable arc discharge, thyristors VS5 and VS6 are switched on and generation of the high-voltage pulses is stopped and welding process is supported due to AC current pulses, passing at supply mains frequency. At that, secondary arc strikes are provided by the fact that voltage, being equal sum of instantaneous value of supply mains and value of voltage set on preliminary charged capacitors $C 1$ or C2 via thyristors VS2 or VS1, respectively, is applied to primary winding I of welding transformer TV1 at the moments of switch of thyristors VS3 and VS4. This 
causes pulse increase of voltage in the interelectrode gap to the value exceeding striking peak $U_{\text {str }}$, at the moments of start of each arc current pulse. Regulation of current flowing through the interelectrode gap is carried out by means of change of thyristors VS3 and VS4 switching angle.

The following advantages can be referred to the power sources, designed in accordance with scheme given in Figure 2, namely their capability to provide contact-free initial arc striking as well as its re-ignition during welding, possibility of reduction of weight-dimension characteristics of power sources due to relatively small size of phase generator set into the primary circuit and using welding transformers with fixed positioning of their primary and secondary winding and reduced to 45-48 V open-circuit voltage. At the same time, except for disadvantages including typically low indices of electromagnetic compatibility (EMC), which are fundamental characteristic to all TT with intermittent arc current and phase regulator in the primary winding $[2,4,5]$. The described power source is characterized by pronounced dependence of coefficient of welding current waveform on its relative pulse duration in each semi-period and relatively narrow range of this current regulation. Necessity of application of somewhat increased number of thyristors for designing of such a power source results in complication of its regulation system. Based on this, similar power sources are good to be used in SAW, manual welding using large diameter coated electrodes (from $5 \mathrm{~mm}$ ) and can have limited application in TIG-AC welding at current more than $350 \mathrm{~A}$.

Investigations and experience of application of the devices with arc current phase regulation show that the wider engineering capabilities and higher EMC indices are typical for TT, in which phase regulator is located in the secondary circuit of the welding transformer, and continuity of current flow via the interelectrode gap is achieved with the help of special circuit, being called an infeed circuit and providing filling of dead times in the idle interval of the phase regulator thyristors.

Figure 3 gives insignificantly simplified electrical schematic circuit of power part of the improved power source of this type. The main components of this power source are non-regulated welding transformer $T V 1$, phase regulator based on thyristors VS1 and VS2, CB 1, welding current probe 2 and supplied by mains voltage striker-stabilizer, containing storage capacitor $C 1$ and $C 2$, pulse transformer TV2 with two separate primary windings I and II and output secondary winding III as well as keys with two-side conductance on thyristors VS3-VS6. Welding transformer TV1 is made with one primary winding I and two series and

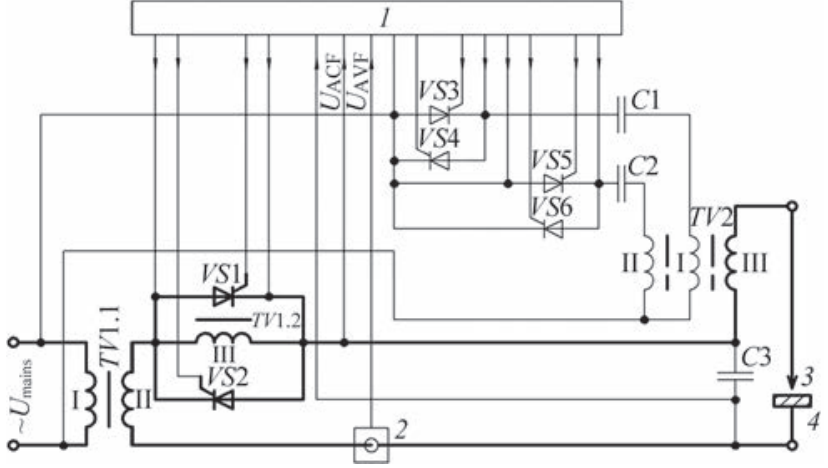

Figure 3. Simplified schematic circuit diagram of power part of improved power source based on TT with phase regulator in the secondary circuit and infeed circuit (designations see in the text)

additive secondary windings II and III. At that, winding II has normal magnetic dissipation, and winding III is of increased one. Welding current regulation and keeping stable its set value under effect of external disturbances and formation of external volt-ampere characteristics (VAC) of the power source are carried out with the help of phase regulator on thyristors VS1, VS2 and $U_{\mathrm{ACF}}, U_{\mathrm{AVF}}$. Feed circuit (current of which makes from 10 to $15 \mathrm{~A}$ ) is formed by secondary windings of welding transformer TV1. Moreover, winding III has parallel connection to phase regulator on thyristors VS1, VS2 due to what VAC of the power source have a form shown in Figure 4.

The peculiarities of design of the infeed circuit lies in the fact that voltage applied to the interelectrode gap at current zero reaches the $U_{\text {op.c tr }}$ value being equal the sum of open-circuit voltages at windings II and III of welding transformer TV1 (see Figure 3).

Formation at initial arc ignition of the high-voltage pulses in a generator of voltage pulses of the striker-stabilizer is provided with the help of circuit containing key on thyristors VS3, VS4, storage capacitor $C 1$ and winding I of pulse transformer TV2. In order to form the increased voltage pulses in a mode of arc

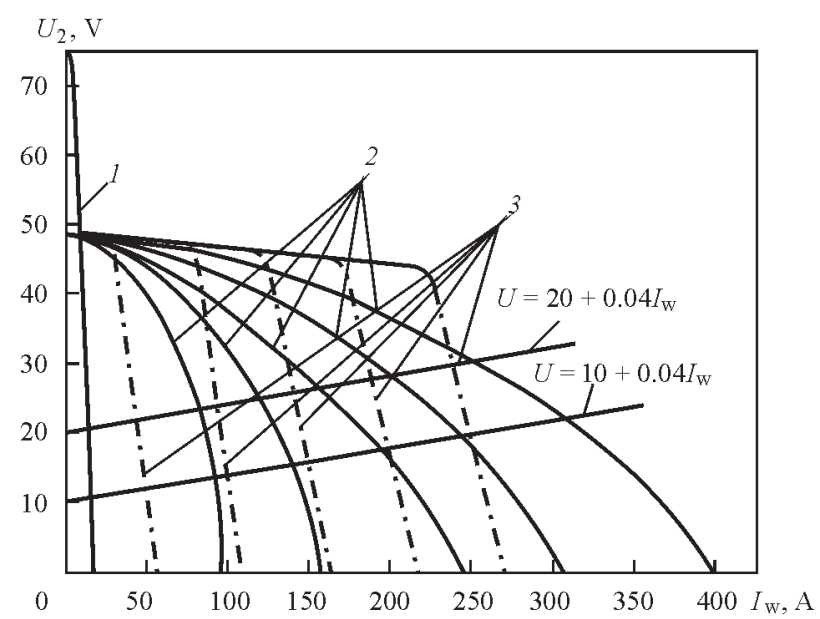

Figure 4. Examples of VAC of improved power source based on TT with phase regulator in the secondary winding and infeed circuit: 1 - infeed circuit; 2 - in MMAW; 3 - in TIG-AC welding mode 
stabilizing a circuit is used consisting of key on thyristors VS5, VS6, storage capacitor C2 and winding II of pulse transformer TV2. From secondary winding III its the high-voltage pulses and increased voltage pulses are injected into the gap between welding electrode 3 and part being welded 4 via protective capacitor C3. Switch of the striker-stabilizer from the mode of initial arc ignition to the mode of arcing stabilizing, and vice versa, is carried out automatically with the help of CB 1 thanks to using coming in it $U_{\mathrm{ACF}}$ and $U_{\mathrm{AVF}}$ signals applying the same algorithm as for striker-stabilizer of power source (see Figure 1).

In comparison with TT, designed according to scheme given in Figure 2, the advantages of power sources, scheme of which corresponds to Figure 3, is possibility to provide significantly wider range of welding current regulation (the lowest value of which can equal the infeed current), lower values of coefficient of current waveform and less effect of this coefficient on welding process stability and other welding properties of power source, possibility of application with TIG-AC welding (including part from aluminum and its alloys) starting from a range of «small» welding currents.

The main disadvantage of the power sources, scheme of which is given in Figure 3, is caused by low rate of variation of infeed current at its polarity change, not exceeding $4 \mathrm{kA} / \mathrm{s}$. This results in reduction of time of deionization of the interelectrode gap, and, respectively, in necessity to build-up energy and amplitudes of increased voltage pulses, generated by the striker-stabilizer, and experimental determination of the moments of start of these pulses generation.

Another disadvantage lies in limitation of welding current regulation depth, increase of which is inevitably related with rise of its form coefficient. The latter has negative effect on durability of coating of stick and wear resistance of non-consumable electrodes [2]. However, regardless the indicated disadvantages, described device has found application in versatile units for MMAW and TIG-AC welding, for example, single-phase welding units I-190 U3.1 and other power sources for AC arc welding, designed based on TT with infeed circuit and pulse stabilization of arcing process.

In addition to power sources, schemes of power blocks of which are given in Figures 1-3, there are AC power sources, containing regulated welding transformer and device for pulse stabilization of arcing (DPSA), which are used in welding engineering for MMAW, SAW and (in limited amount) TIG-AC welding. A series of works is dedicated to the peculiarities, circuit-design solutions, methods of calculation, technological properties and characteristics of industrial specimens of such power sources and DPSA. Works $[4,5]$ outline these issues in more de- tails.. The general disadvantage of all such power sources with DPSA lies in the fact that their design fundamentally eliminates possibility of contact-free initial arc ignition. Besides, such power sources are designed for application of sine-wave mains voltage of only commercial frequency $50(60) \mathrm{Hz}$, due to the fact that rate of variation of welding current close to its zero values remains relatively low, that has negative effect on conditions affecting reliability of arc re-ignition.

Analysis of current tendencies of welding equipment development shows that one of the perspective directions of improvement of AC power sources for MMAW, SAW and TIG-AC welding is application of ICC $[14,27]$ as power modules of these power sources. The ICC with series connection of inductance and capacity gained the widest application in welding power sources. Effect of increase of welding arc stability when using such power sources is caused by the fact that voltage $U_{\mathrm{C}}$ on ICC capacity at welding current zero achieves the largest value, which is $Q$ times ( $Q$ is the welding circuit $Q$-factor) exceeds EMF value of power secondary winding of welding transformer (being equal arc voltage $U_{\mathrm{a}}$ ). Due to this the sum voltage $U_{\mathrm{C}}$ and $U_{\mathrm{a}}$ and rate of arc current variation $d I_{A} / d t$ in the vicinity of current zero point significantly rises [31]. One of the important peculiarities of power sources with ICC is absence in welding current of direct component, that has positive effect on working mode of welding transformer and its weight-dimension indices as well as stability of process of TIG-AC welding of aluminum and its alloys.

Another peculiarity of such power sources lies in the fact that the power sources with ICC among all known welding power sources have the best EMF indices. Theoretical and experimental researches on investigation and determination of welding-technological properties of power sources with ICC, analysis of electromagnetic processes in such power sources and procedure of their design, different aspects of selection and application of element base (in particular, capacitors) in ICC are described in number of works, for example [31-35]. However, fundamental work [14] gives the most complete and detailed consideration of these issues as well as series of original engineering solutions.

Figure 5 shows the structure-functional scheme of improved alternating current power source designed based on ICC (Makhlin, N.M., Korotynsky, O.E., Skopyuk, M.I. Power source for alternating current arc welding. Appl. 10697 a2015 UA. Pat. 03.11.2015). This power source consists of non-regulated welding transformer TV1 with primary winding I and secondary winding II with normal magnetic dissipation and winding III with developed magnetic 
dissipation, phase regulator of welding current 1 , CB 2 , inductive reactor (choke) $L 1$, capacitive reactors $C 1$ and $C 2$, welding current probes 3 and feed current 4 , asynchronous striker-stabilizer 5 with output pulse transformer, secondary winding of which has series connection to welding circuit, two-piston double-pole switch SA1 of voltage supply striker-stabilizer 5, protective capacitor $C 3$. Phase regulator 1 can be made in form of two back-to-back power thyristors, and switch $S A 1$ - in form of two independent AC optical-electronic relay.

The thyristors of phase regulator 1 are switched on at initial stage of welding and open-circuit voltage of power source is determined by open-circuit voltage of infeed circuit, which includes series and additive connected secondary windings II and III of welding transformer $T V 1$, auxiliary inductive reactor $L 1$ and capacitive reactor $C 2$ as well as feed current probe 4 . Two-position double-pole switch $S A 1$ is in a condition providing voltage inflow from winding I of welding transformer TV1 (supply mains voltage) to supply circuit of asynchronous striker-stabilizer 5. Shortterm closing of the gap between welding electrode 6 and part being welded 7 at MMAW or pressing of microswitch set on a torch during TIG-AC or MIG/ MAG welding or pushing of corresponding button of the control system during SAW promote for formation of an enabling signal in CB 2 of power source.

Due to this the signals switching the key of such circuit of striker-stabilizer will come to one of the control inputs of striker-stabilizer 5 from CB 2 at the moments of time corresponding to $(80 \pm 5)$ el. deg. of AC supply mains voltage or AC infeed circuit voltage or open-circuit voltage of infeed circuit of power source. They are determined by CB 2 with the help voltage feedback signals coming from protective capacitor C3. The striker-stabilizer provides for generation of the high-voltage pulses, promoting electric breakdown of the interelectrode gap and appearance in it of spark discharge. This results in impact ionization of the interelectrode gap and creates the conditions for ignition in this gap of a stable arc discharge with the current virtually equal infeed current.

The signal from information output of infeed current probe 4 starts entering the corresponding information input of CB 2 from the movement of appearance of stable arc discharge in the interelectrode gap. Its level is proportional to infeed current that will cause formation in CB 2 of the corresponding control signals and their entering into the control inputs of phase regulator 1, switch $S A 1$ and striker-stabilizer 5. It results in automatic stop of signals from $\mathrm{CB}$ 2 about switch on of circuit key of striker-stabilizer 5 , providing generation of high-voltage pulses, and

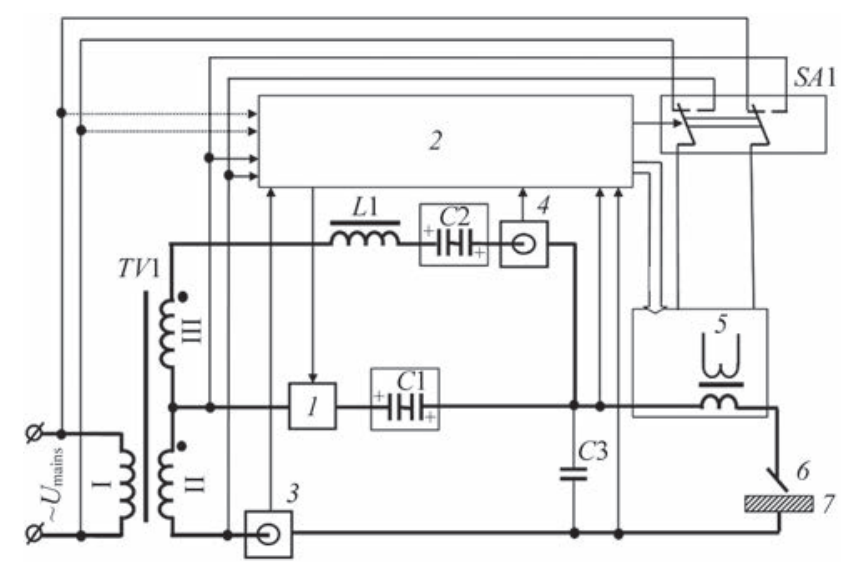

Figure 5. Simplified schematic circuit diagram of power part of improved power source with phase regulator in the secondary circuit and infeed circuit based on ICC (for designations see the text)

commutation of switch SA1 in a state, at which voltage of secondary winding II of welding transformer TV1 will come in supply mains of the striker-stabilizer 5. After that the signals of switching the key of such circuit of striker-stabilizer 5 will come to its corresponding control inputs from $\mathrm{CB} 2$ at the moments of time determined by CB 2 with the help of voltage feedback signals coming from protective capacitor $C 3$ and current feedback signals from information output of infeed current probe 4 . The striker-stabilizer provides for generation of stabilizing pulses of increased voltage.

At the same time, performance of the selected welding cycle is started. Control input of phase regulator 1 receives from CB 2 the signals on switching the thyristors of this phase regulator. At that, indicated signals are the result of processing in $\mathrm{CB} 2$ of the signals of current feedback entering from information input of welding current probe 3 , signals of voltage feedback entering from protective capacitor $C 3$ and signals (limits) determining the values of parameters of selected welding mode. When welding process is finished entering of the signals from information outputs of infeed current 4 and welding current probe 3 to corresponding information inputs of CB 2 is automatically terminated. Open-circuit voltage of infeed circuit is again set at protective capacitor $C 3$. At that, $\mathrm{CB}$ 2 stops generation of the enabling signal and forms an inhibit signal, that results in stop of entering to control inputs of striker-stabilizer 5 and commutation of switch $S A 1$ in a state providing supply of voltage from winding I of welding transformer TV1 in supply mains of striker-stabilizer 5. After that, power source is ready for the next welding cycle.

In comparison with $\mathrm{AC}$ source, scheme of which is given in Figure 3, the improved power source with ICC, designed in accordance with scheme in Figure 5, has such significant advantages as improvement of coefficient of welding current waveform and absence of dependence of this coefficient on switching angle of 
phase regulator thyristors as well as much more higher rate of infeed current variation at change of its polarity. This provides for significantly higher arc stability for welding current regulation extended in area of low current range, and, respectively, wider process capabilities. External VACs of the improved power source with ICC are qualitatively close to shown in Figure 4. Tests of pilot specimens of power source, structure of which corresponds to one given in Figure 5, showed that such power source is capable to provide stability of AC arc and stability of its arcing in welding using stick electrodes virtually with any type of the coating and in SAW using consumable electrode, significantly increase the quality of TIG-welded joints due to increase of resistance of non-consumable electrode and reduction of possibility of defect formation caused by its erosion, obtain satisfactory results in TIG-AC welding of aluminum and its alloys.

At the same time, it is determined that in a series of important cases the rate of infeed current variation at change of its polarity, which is reached in the improved power source with ICC designed for application of mains voltage of industrial frequency, is not enough for realizing high level of stability of TIG-AC welding of aluminum and its alloys. However, this disadvantage can be eliminated by means of 8-10 times increase of frequency of voltage power supply or increase of lev-
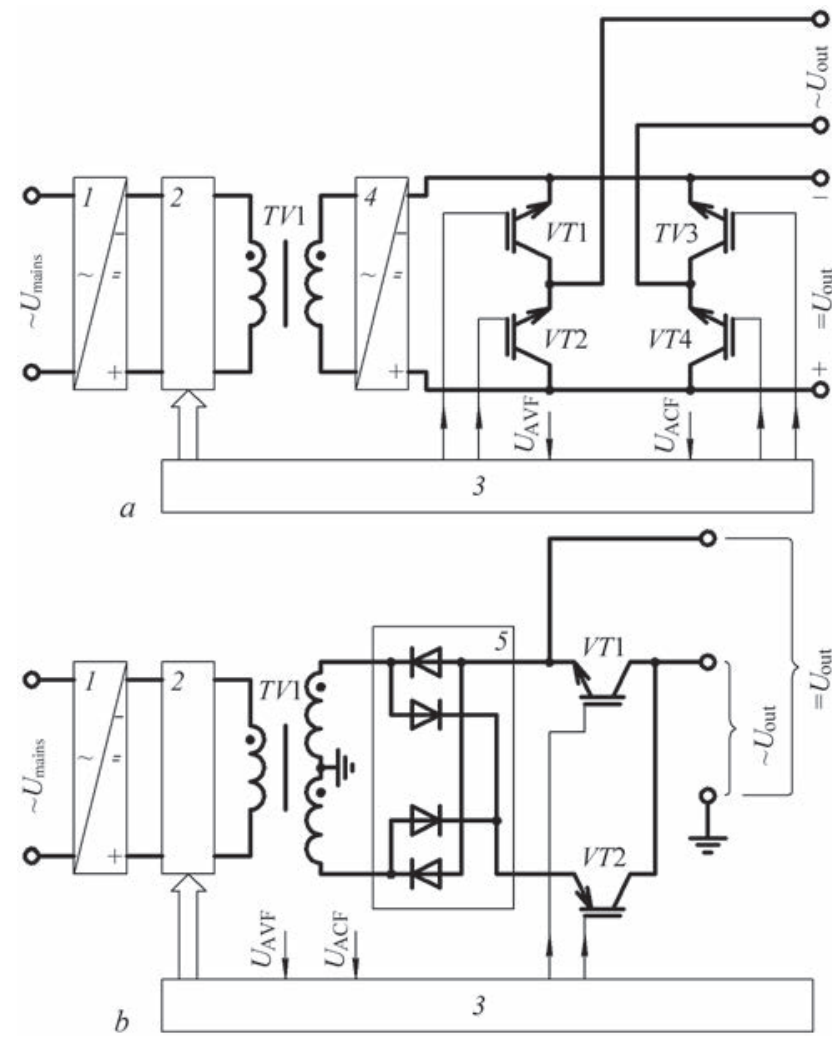

Figure 6. Simplified structure-functional scheme of inverter type power sources with virtually rectangular waveform of alternating welding current (description see in the text): 1 - input (mains) rectifier; 2 - HF converter; 3 - CB; 4 - output HF rectifier; 5 - double-pole output rectifier (with average point) el of energy of stabilizing pulses of increased voltage. Another significant drawback of the improved power source with ICC is caused by the problems typical for ICC of large capacity and related with safety of their capacity reactors. However, effect of these problems can be kept at acceptable level using the methods, means and recommendations, given in work [14].

In whole, carried extensive theoretical and experimental investigations, experience of practical application of different models of sources with ICC, success in current capacitor design, in particular development and mastering of commercial production (based on nanotechnology application) of condensers of super large capacity as well as progress of the recent years in development of new ferromagnetic materials with high saturation induction give ground for assuming that in future welding power sources built based on ICC will seriously compete with inverter type welding power sources and in some cases will push put the latter out.

Together with fulfillment of $U_{2}>U_{\text {str }}$ requirement, another revolutionary measure of increase of $\mathrm{AC}$ arc stability, particularly in TIG-AC welding of aluminum and its alloys, is increase of $d I_{\mathrm{A}} / d t$ to $500-800 \mathrm{kA} / \mathrm{s}$ and more close to the arc current zero point by means of providing rectangular or close to it waveform of this current. In a course of series of decades such a waveform was achieved by means of application of power converters with normal magnetic dissipation in a set with saturation chokes, operating in a mode of forced magnetization (for example, versatile power source TIR-300D) or the same converters, containing bridge phase regulator in their secondary winding, diagonal of direct current of which includes a power choke of large capacity (for example, pulse versatile power source ISVU-315-1 [2, 36].

Commercial production of such sources was stopped in the 1970-1980s due to high consumption of materials and low power indices, however some amount of them is still in operation. Currently TIGAC welding sufficiently widely applies versatile power sources of inverter type, in which virtually rectangular waveform of welding current of $100-400 \mathrm{~Hz}$ frequency can be achieved with the help of output power transistor bridge (Figure 6,a) or using double-pole high-frequency rectifiers and two transistor keys with different type of conductivity (Figure 6,b).

Typical for such power sources $d I_{A} / d t$ values in combination with pulse increase of voltage at the interelectrode gap at arc current polarity change provide for high stability of AC arc burning (including at TIG$\mathrm{AC}$ welding of aluminum and its alloys) in all technologically grounded ranges of arc length and welding current regulation. However, this can provoke some reduction of wear resistance of non-consumable elec- 
trode that, apparently, is explained by impact electrodynamics loads, which at rectangular waveform of welding current effect the non-consumable electrode at each arc current polarity change. Besides, construction of given in Figure 6 power sources for formation of arc alternating current requires mandatory application of auxiliary power transistor keys, each of which should allow passing of current making not less than $60 \%$ of value of the largest arc current, that complicates power part of the source, increase its cost and reduce efficiency. At the same time, it is known fact that if arc alternating current achieves 5-6 A value at MMAW or 3-5 A at TIG welding, then arc discharge in the interelectrode gap can be considered set $[1,4,5]$.

It follows from mentioned above that an alternative for the inverter power sources with high rate of arc current variation at its polarity change can be the power sources, in which at arc current zero the high values of $d I_{A} / d t$ are provided only in $\pm(4-6)$ A range. An example of such an alternating power source can be AC power source (for example TT) with infeed circuit, forming rectangular waveform alternating current. Structural-functional scheme of such a power source, built according to [37], is shown in Figure 7, $a$. This power source includes welding transformer 1 , welding current phase regulator on power regulated semi-conductor keys (for example, back-to-back connected thyristors VS1 and VS2), protective capacitor $C 1$, power transistor keys 2 and 3, auxiliary unregulated DC power sources 4 and 5 of relative small power (up to $0.45 \mathrm{~kW}$ each) and with steep VAC, CB 6, welding current probe 7 , asynchronous striker-stabilizer 8 with output pulse transformer, secondary winding of which is in series with welding circuit.

At the initial stage of welding the algorithms of operation and processes in the power source are similar to the algorithms and processes, taking place in the power sources, schemes of which are shown in Figures 3 and 5. From the moment of setting the arc discharge in the interelectrode gap between welding electrode 9 and part being welded 10 , the corresponding control inputs of welding current phase regulator, transistor key 2 (in positive voltage half-wave) or 3 (in negative voltage half-wave) and striker-stabilizer 8 start receiving pulse signals from CB 6, which gets the welding current feedback signals from welding current probe 7 and arc voltage feedback signals from protective capacitor $C 1$. At that, striker-stabilizer 8 automatically switches from the mode of high-voltage pulse generation for initial arc ignition into the mode of generation of stabilizing increased voltage pulses. Switch on of phase regulator thyristors promotes passing through the interelectrode gap of welding current, representing itself current alternating pulses, amplitude and duration of which is determined by thyristor switch angle (phase).
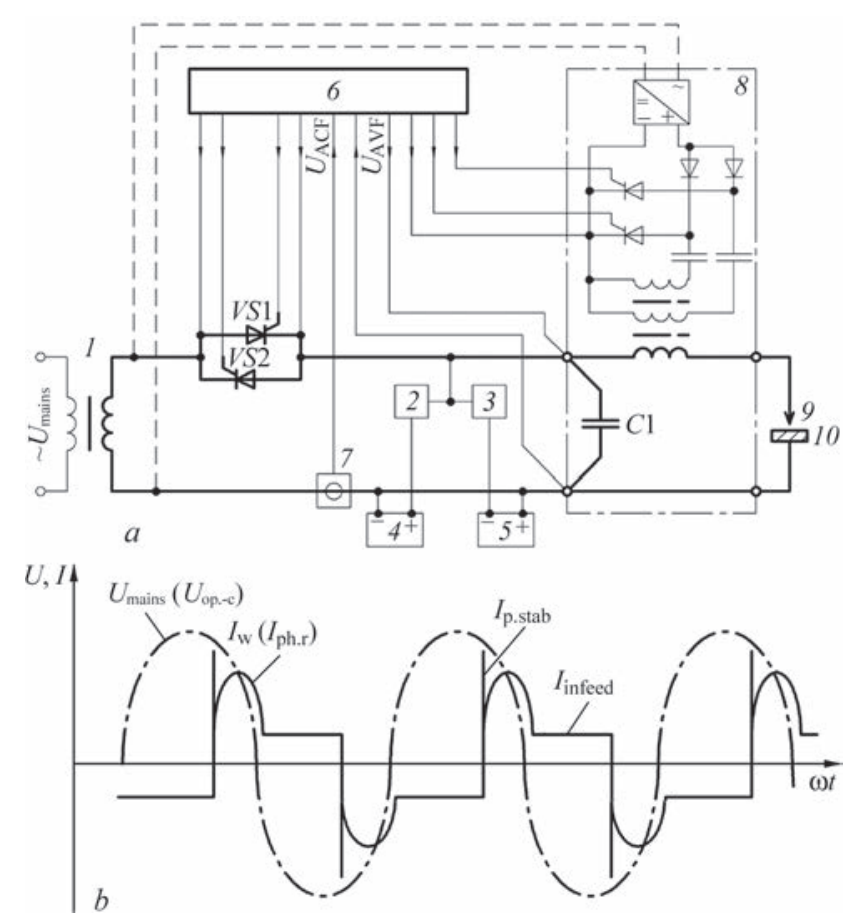

Figure 7. Improved power source with phase regulator and infeed curcuit with current of virtually rectangular waveform: $a-$ simplified structure-functional scheme; $b$ - diagrams of welding current

The dead time between these pulses is filled with infeed current, being supplied depending on its polarity with the help of DC source 4 and key 2 or DC source 5 and key 3. Quick switching of thyristor keys 2 and 3 takes place only at change of welding current polarity and entering in the interelectrode gap of increased voltage stabilizing pulses is realized virtually simultaneous with these switches. Thus, change of infeed current polarity allows achieving its almost rectangular waveform and, respectively, high rate of its change, that in combination with pulse increase of voltage in the interelectrode gap provides for reliable re-ignitions of arc (including at TIG-AC welding of aluminum and its alloys).

Figure 7, $b$ shows typical for this case diagrams of welding current. Regardless some complication of the power part of described power source with rectangular waveform of infeed current, in comparison with other known traditional AC power sources, among its advantages are possibility of reliable functioning at $U_{\text {mains }}$ frequency voltage being equal $50-500 \mathrm{~Hz}$ as well as possibility of application with significant complications of the same approach to infeed circuit architecture in designing TT with phase regulator in the primary circuit or power sources based on ICC. The main structural-schematic solutions, given in Figure 7, a, were used in construction of UDG301M1UKhL4 unit, apparatus N-155 and other units and AC power sources for arc, plasma and microplasma welding. 


\section{Conclusions}

1. Expansion of technological capabilities and increase of stability of AC welding arc can be achieved by means of application of improved power sources, equipped with striker-stabilizers (mainly of asynchronous type with double-circuit generator of voltage pulses and series connection to welding circuit), inluding infeed circuits with rectangular waveform current and providing $d I_{\mathrm{A}} / d t \geq 100 \mathrm{kA} / \mathrm{s}$ at change of arc current polarity.

2. Control systems of the improved power sources should contain in its content arc current and voltage feedback circuits.

3. The most perspective for further improvement of technological and weight-dimension characteristics are TT with rectangular waveform of infeed current, power sources based on ICC and welding power sources of inverter type.

The author expresses thanks to Prof. A.E. Korotynsky and Engs V.Yu. Burayk and D.S. Oliyanenko for help in preparation of this work.

1. Leskov, G.I. (1970) Electric welding arc. Moscow: Mashinostroenie.

2. Belinsky, S.M., Garbul, A.F., Gusakovsky, V.G. et al. (1986) Equipment for arc welding: Refer. Book. Ed. by V.V. Smirnov. Leningrad: Energoatomizdat.

3. (1974) Technology of electric fusion welding of metals and alloys. Ed. by B.E. Paton. Moscow: Mashinostroenie.

4. Dymenko, V.V. (1985) Increase of process stability and extension of technological capabilities of consumable electrode alternating current welding: Syn. of Thesis for Cand. of Techn. Sci. Degree. Kiev: PWI

5. Paton, B.E., Zaruba, I.I., Dymenko, V.V. et al. (2007) Welding power sources with pulsed stabilizing of arcing. Kiev: Ekotekhnologiya.

6. Shmakov, E.I., Makhlin, N.M., Fedotenkov, V.G. et al. (1978) Application of alternating current for welding of low-alloy and alloy steels, aluminium and its alloys. Montazh. i Spets. Raboty $v$ Stroitelstve, 4, 20-22.

7. Paton, B.E., Zavadsky, V.A. (1956) Pulsed arc ignition in gas and manual arc welding. Avtomatich. Svarka, 3, 26-35.

8. Lauzhadis, A.I. (1967) Influence of current frequency on arc stability and process of manual arc welding. Ibid., 9, 29-32.

9. Pentegov, I.V. (1977) Examination of sinusoidal current arc burning conditions with mathematical model of dynamic arc. Ibid., 3, 8-11.

10. Troitsky, V.A. (1975) Influence of electric circuit parameters on re-ignition of alternating current arc. Ibid., 11, 6-10.

11. Lugin, V.P. (1975) Comparative evaluation of arcing stability in stick electrode alternating current welding. Svarochn. Proizvodstvo, 1, 39-40.

12. Pokhodnya, I.K., Gorpenyuk, V.N., Marchenko, A.E. et al. (1979) Procedure of determination of alternating current arc stability. Avtomatich. Svarka, 12, 16-18.

13. Farson, D., Courardy, C., Talkington, J. et al. (1998) Arc initiation in gas metal arc welding. Welding J., 8, 315-321.

14. Korotynsky, O.E. (2007) High-efficient power sources for arc welding based on inductive-capacitive converters: Syn. of Thesis for Dr. of Techn. Sci. Degree. Kiev.
15. Paton, B.E., Lebedev, V.K. (1966) Electric equipment for arc and slag welding. Moscow: Mashinostroenie.

16. Pokhodnya, I.K. (1967) Melting of electrode and interconnection of metals with gases in arc welding: Syn. of Thesis for Dr. of Techn. Sci. Degree. Kiev.

17. Aldenhoff, B.J. Alternating current arc power source. Pat. 3328637A1, USA. Publ. June 1967.

18. Novikov, O.Ya. (1978) Stability of electric arc. Leningrad: Energiya.

19. Pentegov, I.V., Dymenko, V.V., Rymar, S.V. (1995) Selection of open-circuit voltage in sources for alternating current manual arc welding. Avtomatich. Svarka, 5, 35-40.

20. Andrianov, A.A., Sidorets, V.N. (2009) Optimization of stabilizing parameters of alternating current arc welding. Elektrotekhn. i Elektromekhanika, 2, 5-8.

21. Makhlin, N.M. (2015) Peculiarities of contactless ignition of alternating current arc. The Paton Welding J., 10, 29-35.

22. Temkin, B.Ya. (1981) Theory and calculation of welding arc exciters: Syn. of Thesis for Cand. of Techn. Sci. Degree. Leningrad.

23. Lenivkin, V.A., Klenov, G.G., Sagirov, Kh.N. et al. (1986) Arc ignition in consumable electrode welding. Avtomatich. Svarka, 2, 30-34.

24. Makhlin, N.M., Korotynsky, A.E. (2014) Analysis and procedure of calculation of series connection electronic devices for contactless arc excitation. The Paton Welding J., 1, 30-40.

25. Makhlin, N.M., Korotynsky, A.E. (2015) Asynchronous exciters and stabilizers of welding arc. Analysis and design procedure. Pt 1. Ibid., 3/4, 24-35.

26. Makhlin, N.M., Korotynsky, A.E. (2015) Asynchronous exciters and stabilizers of arc. Analysis and calculation procedure. Pt 2. Ibid., 7, 26-37.

27. Lebedev, V.K. (1995) Tendencies of development of power sources for arc welding. Avtomatich. Svarka, 5, 3-6.

28. Fedotenkov, V.G., Makhlin, N.M., Ivanov, V.Ya. Device for alternating current welding. USSR author's cert. 1668068 A1. Int. Cl. B23 K 9/06. Publ. 07.08.1991.

29. Ivanov, G.P., Rozhansky, Z.E., Serdyuk, N.A. (1973) Thyristor current controllers of welding transformers. Avtomatich. Svarka, 11, 65-69.

30. Dudko, D.A., Fedotenkov, V.G., Makhlin, N.M. et al. Device for alternating current welding. USSR author's cert. 935225. Int. Cl. B23 K 9/06, B23 K 9/00. Publ. 15.06.1982.

31. Arlauskas, V.Yu., Narushkyavichus, I.R., Dubashinsky, V.N. et al. (1974) Study of elasticity of welding arc supplied from source with induction and capacity. Svarochn. Proizvodstvo, 10, 14-16.

32. Lebedev, V.K., Narushkyavichus, I.R. (1971) Stability of alternating current arcing in circuit with condenser. Avtomatich. Svarka, 4, 3-5.

33. Narushkyavichus, I.R., Narkyavichus, I.M., Vishnyak, I.S. (1981) Study of multioperator welding source with induction and capacity for welding of alloy steels. In: Abstr. of AllUnion Sci.-Techn. Conf. on Development, Study and Implementation of New Power Sources of Welding Arc (21-22 May 1981), Pt 2, 9-14.

34. Troitsky, V.A. (1981) Method of smooth control of power sources containing longitudinal-capacitive compensation. Avtomatich. Svarka, 5, 8-12.

35. Lebedev, V.K., Korotynsky, A.E. (1994) Alternating current arc in circuit with series induction and capacity. Ibid., 12, 47-48.

36. Goloshubov, V.I. (2005) Welding power sources: Manual. Kiev: Aristej.

37. Fedotenkov, V.G., Makhlin, N.M., Yashunsky, A.Ya. et al. Device for alternating current arc welding. USSR author's cert. 1299725 A1. Int. Cl. B23 K 9/00, 9/06. Publ. 30.03.1987. 